\title{
Sclareol and linalyl acetate are produced by glandular trichomes through the MEP pathway
}

\author{
Camille Chalvin ${ }^{1}$, Stéphanie Drevensek', Françoise Gilard (1)', Caroline Mauve ', Christel Chollet ${ }^{1}$, Halima Morin ${ }^{1}$, \\ Edith Nicol$^{2}$, Eva Héripré ${ }^{3}$, Lucie Kriegshauser ${ }^{1}$, Bertrand Gakière ${ }^{1}$, Michel Dron ${ }^{1}$, Abdelhafid Bendahmane ${ }^{1}$ and \\ Adnane Boualem ${ }^{1 凶}$
}

\begin{abstract}
Sclareol, an antifungal specialized metabolite produced by clary sage, Salvia sclarea, is the starting plant natural molecule used for the hemisynthesis of the perfume ingredient ambroxide. Sclareol is mainly produced in clary sage flower calyces; however, the cellular localization of the sclareol biosynthesis remains unknown. To elucidate the site of sclareol biosynthesis, we analyzed its spatial distribution in the clary sage calyx epidermis using laser desorption/ ionization mass spectrometry imaging (LDI-FTICR-MSI) and investigated the expression profile of sclareol biosynthesis genes in isolated glandular trichomes (GTs). We showed that sclareol specifically accumulates in GTs' gland cells in which sclareol biosynthesis genes are strongly expressed. We next isolated a glabrous beardless mutant and demonstrate that more than $90 \%$ of the sclareol is produced by the large capitate GTs. Feeding experiments, using $1-{ }^{13} \mathrm{C}$-glucose, and specific enzyme inhibitors further revealed that the methylerythritol-phosphate (MEP) biosynthetic pathway is the main source of isopentenyl diphosphate (IPP) precursor used for the biosynthesis of sclareol. Our findings demonstrate that sclareol is an MEP-derived diterpene produced by large capitate GTs in clary sage emphasing the role of GTs as biofactories dedicated to the production of specialized metabolites.
\end{abstract}

\section{Introduction}

Ambergris, a natural perfume ingredient, is a waxy substance secreted by the digestive tract of male sperm whales and the best-known amber odorant natural ingredient ${ }^{1-3}$. Ambergris has been particularly used in the perfume industry for its intense fragrance and unequaled fixative properties ${ }^{4}$. Ambergris properties are mainly due to one of its constitutive components, ambroxide ${ }^{5}$. The growing demand for ambergris-type odorants prompted the search for synthetic alternative routes to ambroxide. The most commonly used route to ambroxide is the hemisynthesis starting from sclareol, natural occurring terpene $e^{6,7}$.

\footnotetext{
Correspondence: Adnane Boualem (adnane.boualem@inrae.fr)

'Université Paris-Saclay, CNRS, INRAE, Univ Evry, Institute of Plant Sciences

Paris-Saclay (IPS2), 91405 Orsay, France

${ }^{2}$ Molecular Chemistry Laboratory (LCM), UMR 9168, CNRS, Ecole Polytechnique, Institut Polytechnique de Paris, Route de Saclay, 91128 Palaiseau Cedex, France Full list of author information is available at the end of the article

These authors contributed equally: Camille Chalvin, Stéphanie Drevensek
}

Sclareol is a natural diterpene originally characterized in clary sage (Salvia sclarea). Salvia is the largest genus of the Lamiaceae family of plants with almost 1000 described species $^{8}$. It is widely spread around the world, as Salvia species are found in both temperate and subtropical regions. Clary sage is a biennial herbaceous species naturally growing in the Mediterranean basin and Western Asia ${ }^{9,10}$. Due to its remarkable aromatic properties, this plant is grown in different European countries, particularly in France, Hungary, and Bulgaria, but also in North America and China ${ }^{11,12}$. Clary sage has been traditionally used as a medicinal plant ${ }^{11}$ and numerous biological effects including anti-inflammatory, antimicrobial and cytotoxic activity have been associated with its flower extracts ${ }^{13,14}$. Today, clary sage is mainly exploited for its aromatic properties. Essential oils (EOs) and sclareol extracted from clary sage are mainly used in flavor and fragrance industries. EOs are extracted by steam distillation of fresh inflorescences and sclareol is

\section{(c) The Author(s) 2021}

(c) (i) Open Access This article is licensed under a Creative Commons Attribution 4.0 International License, which permits use, sharing, adaptation, distribution and reproduction cc) in any medium or format, as long as you give appropriate credit to the original author(s) and the source, provide a link to the Creative Commons license, and indicate if changes were made. The images or other third party material in this article are included in the article's Creative Commons license, unless indicated otherwise in a credit line to the material. If material is not included in the article's Creative Commons license and your intended use is not permitted by statutory regulation or exceeds the permitted use, you will need to obtain permission directly from the copyright holder. To view a copy of this license, visit http://creativecommons.org/licenses/by/4.0/. 
then purified from the remaining plant material by solid/ liquid extraction with an organic solvent ${ }^{15,16}$. EO is used directly as a perfume component for its tenacious, herbaceous, sweaty, and amber odor ${ }^{16}$, while sclareol is used as starting material for the hemisynthesis of ambroxide ${ }^{17}$.

In Angiosperms, terpenoid production is often localized in specialized secretory structures ${ }^{18-22}$. The Lamiaceae are generally characterized by the presence of epidermal secretory structures called glandular trichomes (GTs), which secrete various compounds mainly involved in pollinator attraction or defense against herbivores ${ }^{23}$. Like most members of the Lamiaceae family, clary sage displays two types of GTs: capitate and peltate GTs ${ }^{24,25}$. This classification is based on their distinct morphology: capitate GTs have a long stalk topped by a small spherical secretory head, while peltate GTs are sessile trichomes with a very short stalk and a large flattened glandular head (Fig. S1). Two subtypes of capitate GTs have been described in clary sage according to their size: small and large capitate GTs ${ }^{25}$ (Fig. S1). Linalyl acetate, the acetylated derivative of the monoterpene linalool, is a major component of clary sage EO and is generally considered to be produced by clary sage $\operatorname{GTs}^{11,25}$. By contrast, the localization of sclareol production is less clear. A study using a set of microscopy and analytical chemistry approaches highlighted the presence of abundant epicuticular sclareol crystals at the surface of the calyx ${ }^{15}$. The authors of this study hypothesized that sclareol may be produced by calyx epidermal cells, like other cuticular secretions ${ }^{15}$.

Terpene biosynthesis starts with the condensation of five-carbon building blocks: isopentenyl diphosphate (IPP) and its isomer dimethylallyl diphosphate (DMAPP), to form linear compounds called prenyl intermediates. Prenyl intermediates are then converted into functional terpenes through a number of chemical modifications, for example, cyclization and hydroxylation ${ }^{26}$. Clary sage diterpene synthases responsible for the production of the diterpene sclareol from geranylgeranyl diphosphate (GGPP) have been identified by three different research groups ${ }^{12,27,28}$. A class II diterpene synthase was shown to catalyze in vitro the conversion of GGPP into a bicyclic intermediate, labda13-en-8-ol diphosphate (LPP) $)^{12,27,28}$. Besides, a class I diterpene synthase was shown to produce sclareol from LPP in vitro ${ }^{12,27}$. When combined in vitro or co-expressed in yeast, these two enzymes catalyze the synthesis of sclareol from GGPP, in two steps ${ }^{12,27}$.

Genes involved in the biosynthesis of linalyl acetate in clary sage have not been identified so far, but the biosynthesis of this monoterpene has been investigated in several mint species ${ }^{29,30}$. In lemon mint (Mentha aquatica var. citrata, Lamiaceae), linalyl acetate is obtained after acetylation of the monoterpene linalool, which is produced in one step from GPP through the action of a linalool-synthase $\mathrm{e}^{30}$.
In plants, IPP and DMAPP are produced by two distinct metabolic pathways: the mevalonate pathway (MVA pathway) and the methylerythritol-phosphate pathway (MEP pathway) ${ }^{31,32}$. As the MVA and MEP pathways are localized in different compartments of the plant cell, cytosol, and plastids, respectively, their respective activities generate two separate pools of IPP and DMAPP (Fig. S2). In agreement with the subcellular localization of the corresponding enzymes, the biosynthesis of downstream products generally depends on only one of these two pools ${ }^{33}$. Most sesquiterpenoids originate from the MVA pathway, while the majority of mono- and diterpenoids derive from the MEP pathway ${ }^{34}$. However, a growing number of studies describe the production of terpenoids of mixed origin, i.e., made of five-carbon units originating from both pathways ${ }^{33,35,36}$. Indeed, prenyl intermediates can be exchanged between the two compartments thereby enabling the connection between the MVA and MEP pathways ${ }^{37}$. The metabolic origin of sclareol and linalyl acetate in clary sage has not been investigated in this context.

To elucidate the site of sclareol and linalyl acetate biosynthesis, we analyzed the spatial distribution of sclareol and linalyl acetate at the surface of the clary sage calyx, using Laser desorption/ionization (LDI) mass spectrometry imaging (MSI). In addition, we investigated the expression of sclareol biosynthesis genes in isolated GTs. Our data show that sclareol and linalyl acetate are mainly produced in GTs. Pathway-specific labeling and inhibitors studies further indicate that the MEP pathway is the main channel for the production of IPP and DMAPP leading to sclareol and linalyl acetate biosynthesis. Finally, we isolated and characterized a glabrous clary sage line to genetically validate the role of GTs in sclareol and linalyl acetate biosynthesis and storage. Our findings demonstrate that most of the sclareol and linalyl acetate found in clary sage is produced by the large capitate GTs, providing new insights in the processes involved in terpene biosynthesis and accumulation in plants.

\section{Results}

Sclareol and linalyl acetate are highly abundant terpenes of clary sage calyx surface

Studies indicate that the chemical composition of clary sage EO shows important variations and chemotypes have been identified according to the proportion of each compound in the $\mathrm{EO}^{14}$. To characterize the chemical composition of the Vatican White variety of clary sage, we performed gas chromatography-mass spectrometry (GC-MS) analysis of a fully developed calyx extract. Two main metabolites were eluted at 6.20 and $16.98 \mathrm{~min}$, respectively (Fig. S3). The electron ionization (EI)-MS mass spectra obtained from the peak at 6.20 and $16.98 \mathrm{~min}$ were attributed to linalyl acetate $(m / z 196.14633)$ and 
sclareol ( $m / z$ 308.27153), respectively (Fig. S3). To provide a further atomic-resolution structural characterization of the clary sage calyx extract, we performed ${ }^{13} \mathrm{C}-\mathrm{NMR}$ analyses. As for the GC-MS analysis, ${ }^{13} \mathrm{C}$-NMR results show that linalyl acetate and sclareol are the main metabolites in the clary sage calyx extract (Fig. S4).

\section{Sclareol biosynthesis is regulated during calyx development}

Clary sage calyx is the main production site of linalyl acetate and sclareol ${ }^{15}$; however the production dynamic of these two metabolites, during calyx development, has not been investigated. To explore their production kinetic, linalyl acetate and sclareol were quantified by GC-MS at different stages of calyx development (Fig. 1a, b). We found sclareol and linalyl acetate accumulation starting at the early bud stage, where they represent $7.5 \%$ and $4.5 \%$ of calyx dry mass, respectively (Fig. 1a-d). Then, the accumulation of sclareol and linalyl acetate gradually increases, reaching a maximum at the corolla abscission stage (Fig. 1c). We found sclareol and linalyl acetate, at the corolla abscission stage, present in comparable amount at $\sim 0.4 \mathrm{mg} /$ calyx (Fig. 1c), making $\sim 6 \%$ of calyx dry mass (Fig. 1d). At the calyx senescence stage we observed a significant decrease in sclareol and linalyl acetate content (Fig. 1c, d). The observed decrease in linalyl acetate content could be explained by the evaporation of this volatile molecule ${ }^{25}$. However, the decrease in the concentration of sclareol is unlikely due to evaporation, given its very low vapor pressure $\left(0.000435 \mathrm{mmHg}\right.$ at $\left.25^{\circ} \mathrm{C}\right)$ and that it was not absorbed in clary sage headspace experiments $^{25}$.

\section{Sclareol and linalyl acetate biosynthesis is inhibited by FOS} in a dose-dependent manner

In plants, the isoprenoid precursors IPP and DMAPP are produced by the cytosolic MVA and plastidial MEP pathways $^{31,32}$ (Fig. S2). To investigate the contribution of MVA and MEP pathways to sclareol and linalyl acetate biosynthesis, we used specific inhibitors of each pathway, mevinolin (MEV) and fosmidomycin (FOS). MEV is a competitive inhibitor of 3-hydroxy-3-methylglutaryl (HMG) coenzyme A (CoA) reductase (HMGR), a rate-limiting enzyme of the MVA pathway that catalyzes the conversion of HMG-CoA to mevalonate (MVA) ${ }^{38}$. FOS competitively inhibits the 1deoxy-D-xylulose 5-phosphate reductoisomerase (DXR), a key regulatory enzyme in the MEP pathway that catalyzes

a

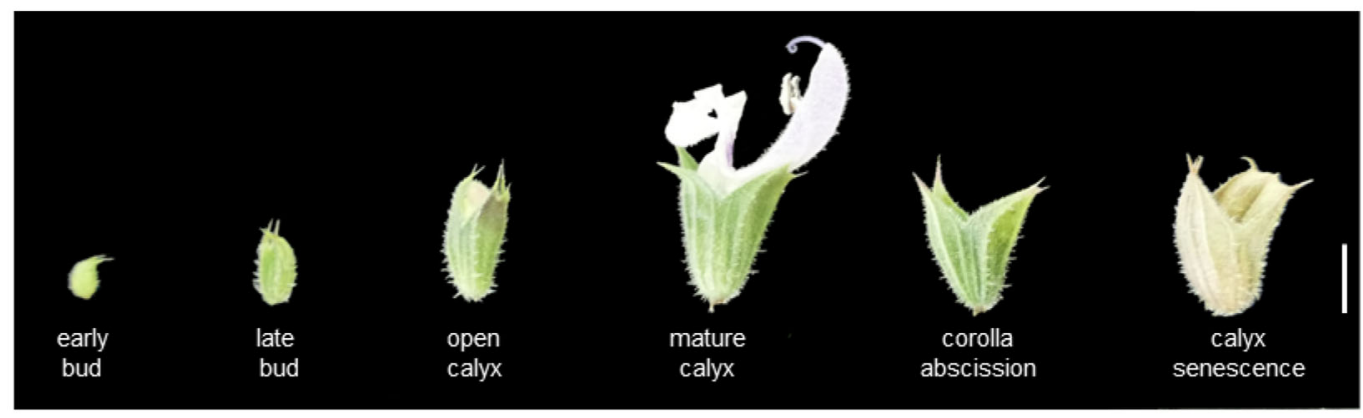

b

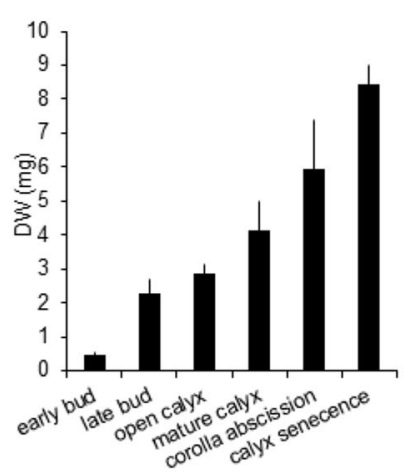

C

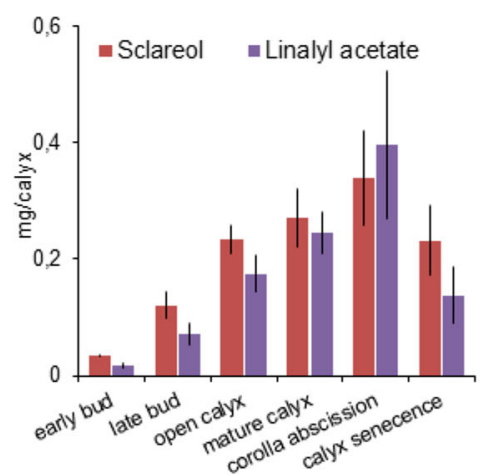

d

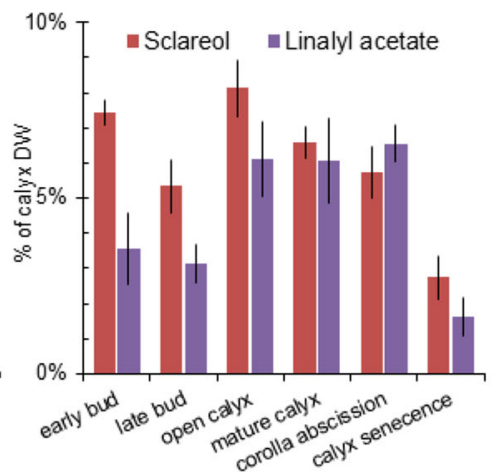

Fig. 1 Sclareol and linalyl acetate accumulation during calyx development. a Clary sage flower development stages. b Flower dry weight was measured after hexane extraction. Hexane extraction was performed without removing the developing corolla from the early bud and late bud stages. c Sclareol and linalyl acetate content at different calyx developmental stages. $\mathbf{d}$ Sclareol and linalyl acetate content expressed as a percentage of calyx dry weight. Bars represent the mean \pm SD $(n=5)$. Scale bar: $5 \mathrm{~mm}$ 


\section{a}

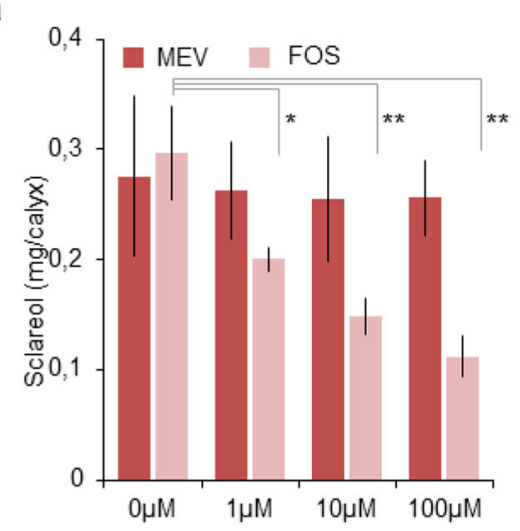

b

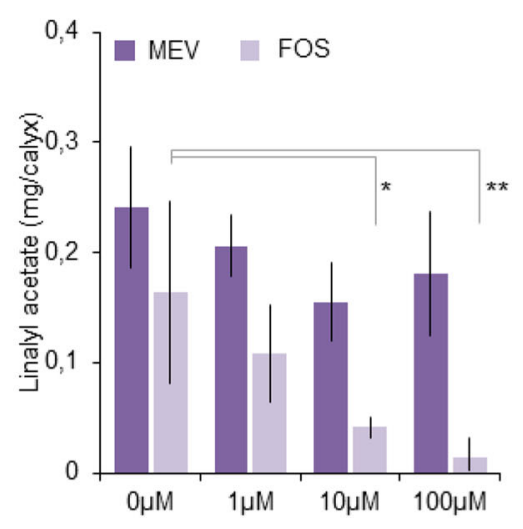

Fig. 2 Impact of mevinolin or fosmidomycin treatment on sclareol and linalyl acetate content. Clary sage cut inflorescences were fed with a solution containing mevinolin or fosmidomycin for 6 days. Sclareol (a) and linalyl acetate (b) content was quantified by gas chromatography coupled to mass spectrometry (GC-MS) after hexane extraction. Bars represent the mean \pm SD $(n=4)$. Stars indicate the results of the Student's $t$ test $\left({ }^{*} p<0.05,{ }^{* *} p<0.01\right)$

the conversion of 1-deoxy-D-xylulose 5-phosphate (DXP) to 2-C-methyl-D-erythritol 4-phosphate (MEP) ${ }^{31}$.

To assess the effect of MEV and FOS, clary sage cut inflorescences were fed with different concentrations of inhibitor, and sclareol and linalyl acetate content were quantified by GC-MS after 6 days. As shown in Fig. 2, FOS treatment inhibits sclareol and linalyl acetate production in a dose-dependent way. At $100 \mu \mathrm{M}$ FOS, sclareol and linaly acetate contents are reduced by $70 \%$ and $97 \%$, respectively, compared with control inflorescence fed only with the nutritive solution (Fig. 2a, b). In contrast, MEV treatment had no effect on the linalyl acetate and sclareol contents (Fig. 2a, b). These results strongly suggest that the MEP pathway is the main source of isoprenoid precursors for both the monoterpene linalyl acetate and the diterpene sclareol biosynthesis in clary sage. The results also indicate that the MVA pathway does not contribute to linalyl acetate and sclareol production.

\section{Sclareol and linalyl acetate are MEP-derived terpenes}

To confirm the role of the MEP pathway in linalyl acetate and sclareol biosynthesis, clary sage cut inflorescences were fed with the stable isotope tracer $1-{ }^{13} \mathrm{C}$-glucose. Sclareol and linalyl acetate ${ }^{13} \mathrm{C}$-labeling patterns were then analyzed by ${ }^{13} \mathrm{C}$-NMR. Depending on the isoprenoid precursor biosynthesis routes, the metabolism of $1-{ }^{13} \mathrm{C}$-glucose gives rise to a specific carbon labeling pattern in IPP and DMAPP ${ }^{33}$ (Fig. S5). Theoretical sclareol and linalyl acetate ${ }^{13} \mathrm{C}$-labeling patterns expected in each case (Fig. S5a) were then inferred based on described enzymatic mechanisms ${ }^{12,27-30}$. If sclareol is synthesized through the MEP pathway, carbons at position $\mathrm{C}-2,-6,-11$, and -15 would be specifically labeled, whereas if it derives from the MVA pathway, carbons would be specifically labeled at position $\mathrm{C}-1,-3,-5,-7$,
$-9,-12,-14$, and -18 (Fig. S5b, c). Sclareol carbons C$16,-17,-19$, and -20 would be labeled via either the MEP or MVA pathway whereas C- $4,-8,-10$, and -13 carbons would never be labeled. Thanks to the high resolution of the NMR spectra of sclareol and linalyl acetate, signals of carbon atoms have been assigned unambiguously to all the positions $\mathrm{C}-1$ to $\mathrm{C}-20$ for sclareol and C-1 to C-12 for linalyl acetate (Fig. S4).

Consistent with the ${ }^{13} \mathrm{C}$-labeling prediction, ${ }^{13} \mathrm{C}$ NMR spectrum of $1-{ }^{13} \mathrm{C}$-glucose fed clary sage shows high ${ }^{13} \mathrm{C}$ abundance for $\mathrm{C}-2,-6,-11,-15,-16,-17,-19$, and -20 atoms of sclareol. In contrast, ${ }^{13} \mathrm{C}$ abundance for $\mathrm{C}-1$, $-3,-4,-5,-7,-8,-9,-10,-12,-13,-14$, and -18 carbons was very low (Figs. 3a and S3). Similarly, for linalyl acetate, high ${ }^{13} \mathrm{C}$ abundance was recorded for $\mathrm{C}-1$, $-5,-8,-10$, and -12 whereas it was very low for $C-2$, $-3,-4,-6,-7,-9$, and 11 carbons (Figs. $3 \mathrm{~b}$ and S3).

To assess the effect of MVA and MEP pathway inhibitors on the sclareol and linalyl acetate ${ }^{13} \mathrm{C}$ labeling, MEV and FOS were added to the feeding solution together with ${ }_{1-}^{13} \mathrm{C}$-glucose. FOS almost completely abolishes the ${ }^{13} \mathrm{C}$ labeling of all carbons of sclareol and linalyl acetate, whereas the ${ }^{13} \mathrm{C}$ labeling observed in presence of MEV is comparable to the control (Fig. 3a, b).

Taken together, the MEV and FOS inhibition data and the $1{ }^{13} \mathrm{C}$-glucose tracer results strongly support the conclusion that sclareol and linalyl acetate biosynthesis depends on the plastidial IPP and DMAPP produced by the MEP pathway.

\section{Sclareol and linalyl acetate are spatially localized in GTs}

Plant metabolomics analyses allow the detection of thousands of metabolites from whole tissues homogenate $^{39}$, but the process destroys and oversimplifies the spatial tissue organization. For example, a leaf epidermis often comprises pavement, guard, trichome, and 


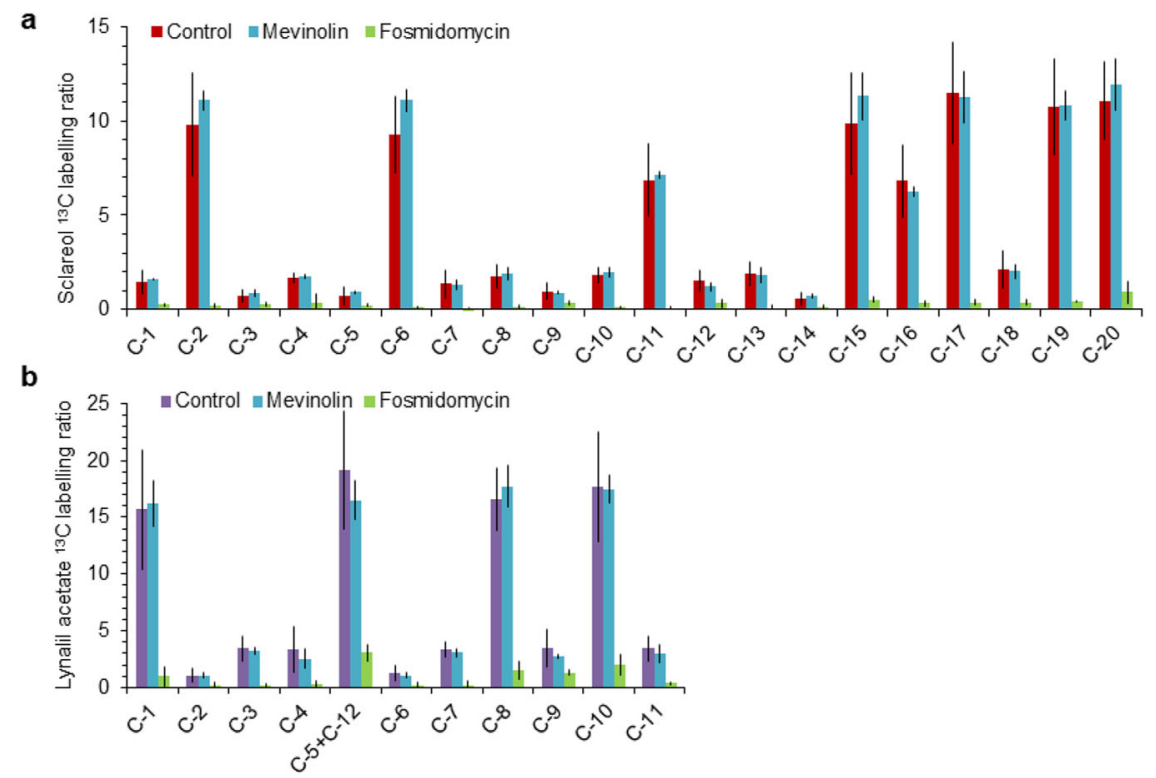

Fig. 3 Sclareol and linalyl acetate ${ }^{13} \mathrm{C}$-labeling after feeding with $1-{ }^{13} \mathrm{C}$-glucose and terpene biosynthesis inhibitors. Clary sage cut inflorescence stems were fed with a solution containing $1-{ }^{13} \mathrm{C}$-glucose or standard glucose with $100 \mu \mathrm{M}$ of mevinolin, $100 \mu \mathrm{M}$ of fosmidomycin, or no inhibitor (control) for 5 days. Sclareol (a) and linalyl acetate (b) ${ }^{13} \mathrm{C}$-labeling was analyzed by quantitative ${ }^{13} \mathrm{C}$ nuclear magnetic resonance $\left({ }^{13} \mathrm{C}-\mathrm{NMR}\right)$ after hexane extraction. The labeling ratio was calculated as follows: (Peak arealabeled glucose - Peak area $a_{\text {standard }}$ glucose)/Peak area standard glucose. $_{\text {Bars }}$ represent the mean $\pm \mathrm{SD}(n=3)$

glandular cells known to have different metabolic profiles. Visualization of the metabolites' distribution is therefore central to provide cellular and site-specific context for the biosynthesis of target metabolites.

To image and perform in situ metabolic mapping, we use the matrix-free LDI-MSI on fresh clary sage calyx that has not undergone any pretreatment. Ion detection and quantification were performed by Fourier transform ion cyclotronic resonance (FT-ICR), a high-resolution mass spectrometry technique allowing reliable identification of compounds in a complex mixture of chemicals such as found at the surface of plant epidermis ${ }^{40}$. A representative single-pixel mass spectrum from the calyx surface is shown in Fig. 4a. Sclareol $(\mathrm{S}, \mathrm{m} / z$ 308.2715) is detected as a monomer $[\mathrm{S}+\mathrm{K}]^{+}(m / z 347.2354, \Delta m / z=0.95 \mathrm{ppm})$ and a dimer potassium adduct $[\mathrm{S}+\mathrm{S}+\mathrm{K}]^{+}(\mathrm{m} / z$ 655.5095, $\Delta m / z$ $=2.04 \mathrm{ppm}$ ). Dimers ion adducts often form when the molecule is present at a high concentration ${ }^{41-43}$. In line with the GC-MS analysis (Fig. S3), the LDI-FT-ICR spectrum shows that the most abundant ions correspond to sclareol ion adducts indicating that sclareol is highly concentrated in the clary sage calyx (Fig. 4a).

Similarly, linalyl acetate $(\mathrm{L}, \mathrm{m} / z$ 196.14633) is detected as monomer potassium adduct $[\mathrm{L}+\mathrm{K}]^{+}(\mathrm{m} / z$ 235.1095, $\Delta m / z=-3.66 \mathrm{ppm})$. In contrast to sclareol, the dimer potassium adduct $[\mathrm{L}+\mathrm{L}+\mathrm{K}]^{+}(\mathrm{m} / z$ 431.2558) was detected at a very low concentration probably because of the high vacuum applied during the experiment and because linalyl acetate is a volatile monoterpene.
After LDI-MSI spectra acquisition at a pixel size of $25 \mu \mathrm{m}$, our data included 6614 metabolite images. Figure $4 \mathrm{~b}-\mathrm{i}$ shows the optical and ion distribution images of sclareol and linalyl acetate at the calyx surface. The spatial distribution of $[\mathrm{S}+\mathrm{K}]^{+},[\mathrm{S}+\mathrm{S}+\mathrm{K}]^{+},[\mathrm{L}+\mathrm{K}]^{+}$, and $[\mathrm{L}$ $+\mathrm{L}+\mathrm{K}]^{+}$exhibits strong similarities. $[\mathrm{L}+\mathrm{K}]^{+},[\mathrm{S}+\mathrm{K}]^{+},[\mathrm{L}$ $+\mathrm{L}+\mathrm{K}]^{+}$, and $[\mathrm{S}+\mathrm{S}+\mathrm{K}]^{+}$ions are observed as intense colocalized spots that correspond to calyx large capitate GTs (Fig. 4b-i). Surprisingly, $[\mathrm{S}+\mathrm{K}]^{+}$ion distribution was not exclusively restricted to the area corresponding to the large capitate GTs (Fig. 4c). In contrast, no $[\mathrm{S}+\mathrm{K}]^{+}$, $[\mathrm{S}+\mathrm{S}$ $+\mathrm{K}]^{+},[\mathrm{L}+\mathrm{K}]^{+}$, and $[\mathrm{L}+\mathrm{L}+\mathrm{K}]^{+}$ions have been observed in non-GTs, small capitate and peltate GTs. These results suggest that linalyl acetate and sclareol are most probably biosynthesized in large capitate GTs.

\section{Diterpene and sclareol biosynthesis genes are expressed in GTs}

LDI-FT-ICR imaging alone can only provide conclusive information about the spatial distribution of linalyl acetate and sclareol. To confirm the metabolic imaging results and bring molecular evidence for the metabolite biosynthesis, we assessed the expression of selected genes in GT heads isolated from calyces and in calyces before abrasion (Fig. 5a-c).

Because sclareol and linaly acetate derive from the MEP pathway (Figs. 2 and 3), the expression analysis focused on the MEP biosynthetic genes DXS2, DXR, MCT, CMK, $H D S$, and $H D R$ (Fig. S2) and genes involved in sclareol production, GGPPS, LPPS, and $S c S^{12}$. The real-time gene 


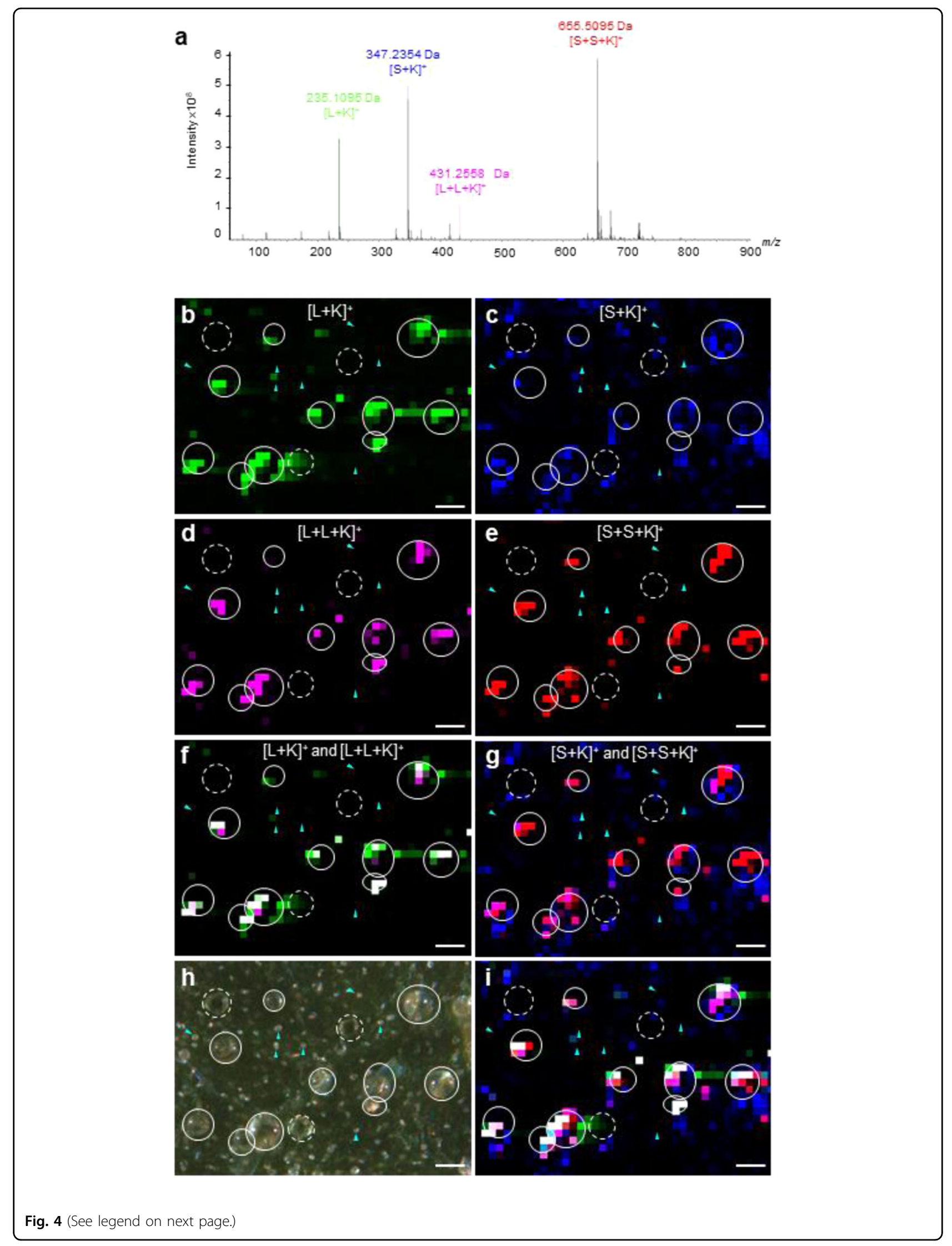


(see figure on previous page)

Fig. 4 Localization of sclareol and linalyl acetate at the surface of a clary sage calyx. The chemical composition of the epidermal surface of clary sage calyces was analyzed through laser desorption-ionization followed by FT-ICR mass spectrometry (LDI-FT-ICR). a Representative mass spectrum of the surface of a clary sage calyx. Spatial distribution of $[\mathrm{L}+\mathrm{K}]^{+}$ions $(\mathbf{b}),[\mathrm{L}+\mathrm{L}+\mathrm{K}]^{+}$ions $(\mathbf{d}),[\mathrm{S}+\mathrm{K}]^{+}$ions $(\mathbf{c})[\mathrm{S}+\mathrm{S}+\mathrm{K}]^{+}$ions $(\mathbf{e})$ and at the surface of the calyx sample. f Overlay of $[\mathrm{L}+\mathrm{K}]^{+}$and $[\mathrm{L}+\mathrm{L}+\mathrm{K}]^{+}$ions. $\mathbf{g}$ Overlay of $[\mathrm{S}+\mathrm{K}]^{+}$and $[\mathrm{S}+\mathrm{S}+\mathrm{K}]^{+}$ions. $\mathbf{h}$ Top view of a clary sage calyx sample observed with a zoom stereomicroscope. i Overlay of $[\mathrm{L}+\mathrm{K}]^{+},[\mathrm{L}+\mathrm{L}+\mathrm{K}]^{+},[\mathrm{S}+\mathrm{K}]^{+}$, and $[\mathrm{S}+\mathrm{S}+\mathrm{K}]^{+}$ions. Blue arrowheads indicate short capitate glandular trichomes, circles indicate large capitate glandular trichomes, dashed circles indicate peltate glandular trichomes. L linalyl acetate, S sclareol, Scale bar: $100 \mu \mathrm{m}$
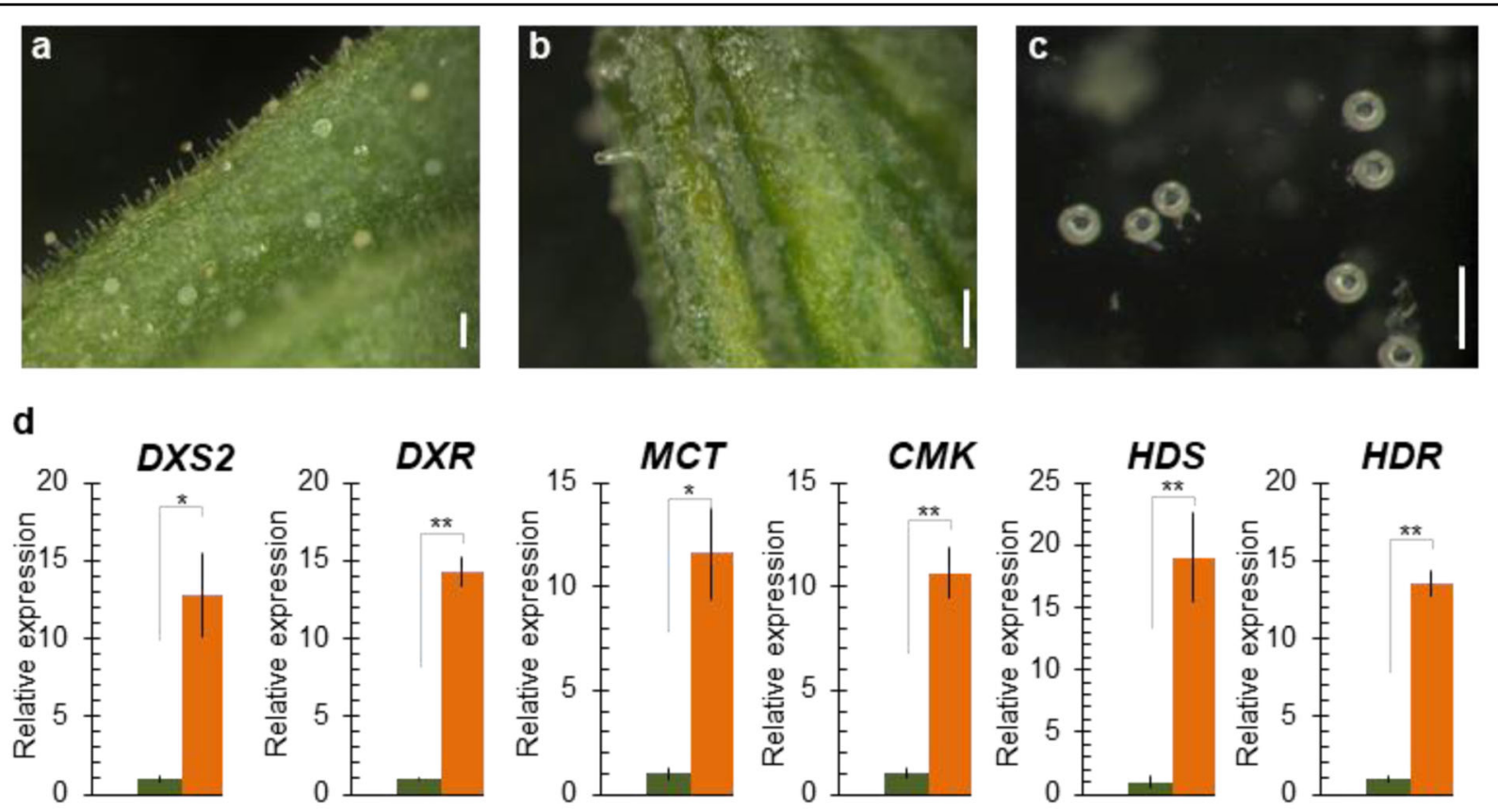

e
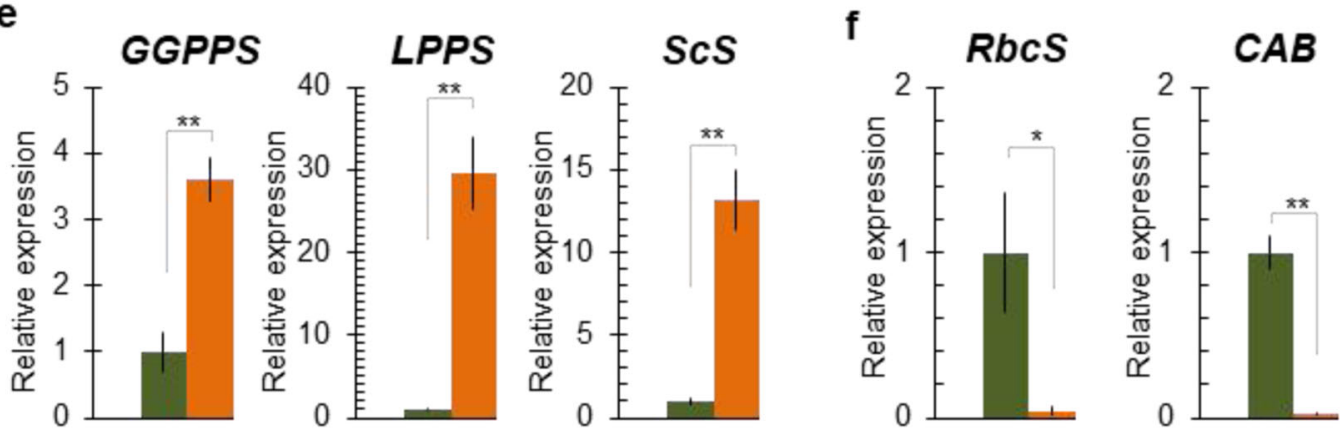

Calyx before abrasion

Glandular trichome heads

Fig. 5 MEP and sclareol biosynthesis genes are expressed in isolated glandular trichome heads. $\mathbf{a}$, b Clary sage calyx before (a) and after (b) abrasion of the surface with glass beads. c Purified glandular trichome heads. Scale bar: $200 \mu \mathrm{m}$. d, e Relative gene expression of MEP (d), sclareol (e), and photosynthesis (f) genes in calyx before abrasion (dark green) and purified glandular trichome heads (orange). MEP biosynthesis genes: DXS2 1 deoxy-D-xylulose-5-phosphate synthase 2, DXR 1-deoxy-D-xylulose-5-phosphate reductoisomerase, MCT 2-methyl-D-erythritol-4-phosphate cytidylyltransferase, CMK 4-diphosphocytidyl-2-methyl-D-erythritol kinase, HDS 4-hydroxy-3-methylbut-2-enyl-diphosphate synthase, HDR 4-hydroxy3-methylbut-2-enyl-diphosphate reductase. Sclareol biosynthesis genes: GGPPS geranylgeranyl-diphosphate synthase, LPPS labda-13-en-8-oldiphosphate synthase, ScS sclareol synthase. Photosynthetic genes. RbcS ribulose-bisphosphate carboxylase small chain, CAB chlorophyll a-b binding protein. Bars represent the mean \pm SD $(n=4)$. Stars indicate the results of Student's $t$ test $\left(^{*} p<0.05,{ }^{* *} p<0.01\right)$

expression analysis shows that all MEP and sclareol biosynthetic genes were highly expressed in GT heads compared to calyx before abrasion (Fig. $5 \mathrm{~d}$, e). The level of DXS2, DXR, CMS, CMK, HDS, HDR, LPPS, and ScS transcripts is markedly higher in isolated GTs with a 10to 30-fold relative expression ratio compared to that in calyx before abrasion. GGPPS expression is also higher in GTs with a 2.5-fold comparative ratio (Fig. 5e). By 

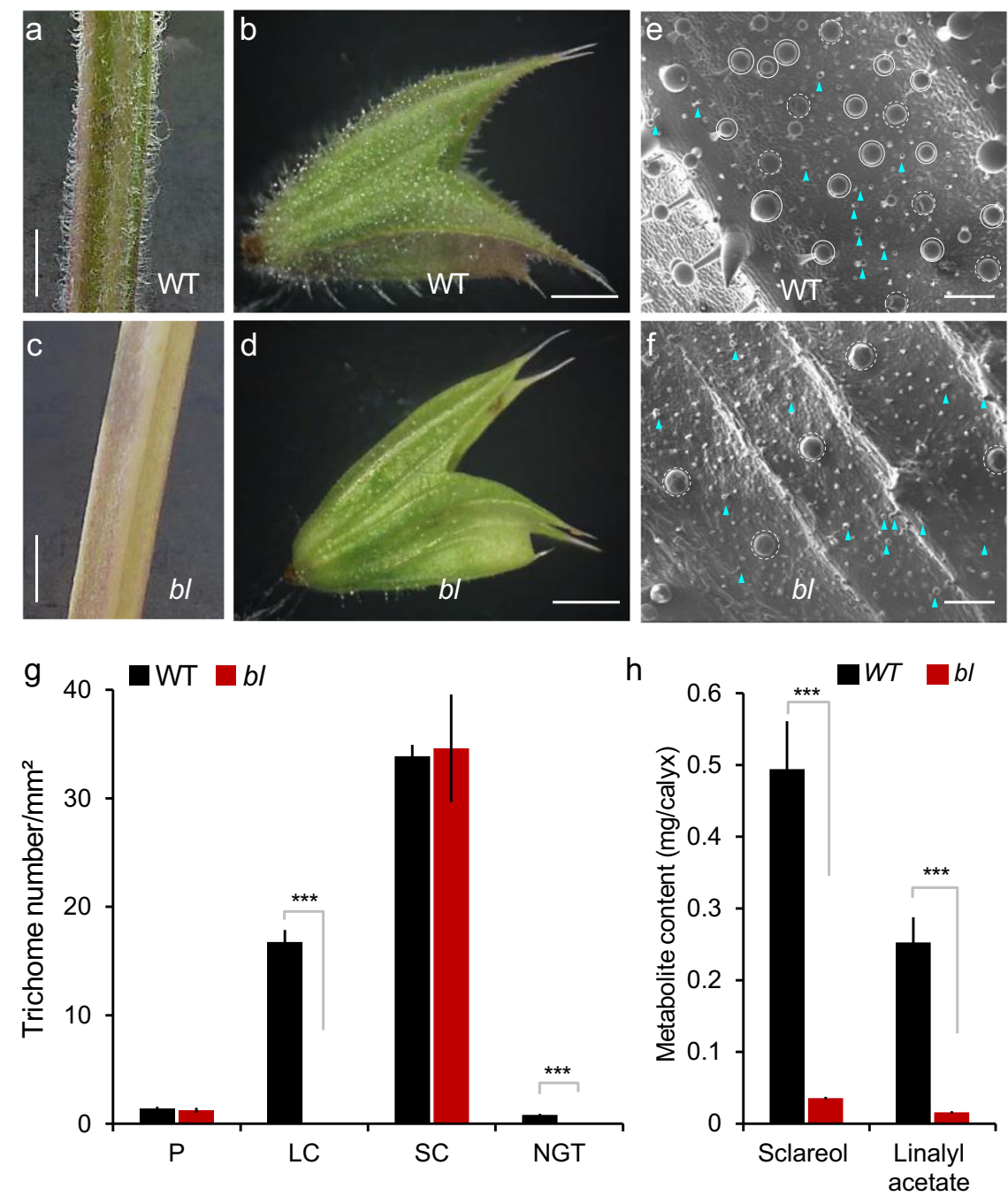

Fig. 6 The beardless mutant of clary sage displays reduced glandular trichomes density and sclareol and linalyl acetate content.

a-d Phenotype of the wild-type (WT) and beardless (b/) mutant. $\mathbf{a}, \mathbf{c}$ Young stem; $\mathbf{b}$, $\mathbf{d}$ calyx; scale bar: $4 \mathrm{~mm}$. e, $\mathbf{f}$ Scanning electron microscopy of the WT (e) and beardless (f) calyx. Blue arrowheads indicate short capitate glandular trichomes, circles indicate long capitate glandular trichomes, dashed circles indicate peltate glandular trichomes. Scale bar: $300 \mu \mathrm{m}$. g Density of different trichome types at the surface of calyces from WT and beardless plants. Bars represent the mean \pm SD (WT, $n=9$; beardless mutant, $n=10)$. P peltate glandular trichomes, LC large capitate glandular trichomes, SC small capitate glandular trichomes, NGT nonglandular trichomes. $\mathbf{h}$ Sclareol and linalyl acetate content in the WT and beardless mutant plants. Bars represent the mean $\pm S D(W T, n=18$; beardless mutant, $n=12)$. Stars indicate the results of the Student's $t$ test $\left.*^{* * *} p<0.0001\right)$

contrast, genes encoding proteins involved in photosynthesis, $R b c S$ and $C A B$, are predominantly expressed in calyx before abrasion compared to GT heads (Fig. 5f). This observation suggests that there is no or low photosynthetic activity in clary sage GTs is low or absent, as previously reported for mint peltate $\mathrm{GTs}^{44,45}$. Taken together, these results confirm that terpenoid biosynthesis, in particular sclareol biosynthesis, mainly occurs in GT heads, in accordance with the data obtained with our LDI-FT-ICR experiments (Fig. 4). Moreover, the fact that the photosynthetic activity is reduced in clary sage GTs suggests that carbon assimilates are transported from neighboring cells to GTs to feed the MEP pathway.

\section{Large capitate GTs are the main production site of sclareol} and linalyl acetate

To provide direct genetic evidence for the role of GTs in the production of sclareol and linaly acetate, we generated a clary sage EMS mutant collection and phenotypically screened 4500 EMS M2 families. We isolated several mutants altered in GT development and density. Among them, the V86 mutant showed a strong glabrous phenotype and was further characterized (Fig. 6a-f).

To assess the inheritance of the glabrous phenotype, the V86 mutant was backcrossed to the clary sage parental line (wild type (WT)) to obtain a BC1F2 segregating population. Among 67 plants, 49 showed a WT GT 
density and 18 showed a glabrous phenotype in accordance with a 3:1 segregation ratio (WT/glabrous, chisquare test, $p<0.01)$. These results indicate that the glabrous phenotype is controlled by a single recessive gene. We named this locus beardless $(b l)$.

Scanning electron microscopy imaging of calyces and careful numbering of the different trichome types, GTs and non-GTs, showed that the glabrous phenotype of $b l$ mutant plants is due to a complete loss of the large capitate GTs and non-GTs (Fig. 6g). In contrast, the number of peltate and small capitate GTs remains unchanged (Fig. 6g). This result indicates that the development of large capitate GTs and non-GTs share common genetic mechanisms and surprisingly that large capitate, small capitate, and peltate GTs develop through distinct regulatory pathways.

To assess the contribution of large capitate GTs to the clary sage metabolite production, sclareol and linalyl acetate were quantified by GC-MS (Fig. 6h). Metabolite quantification shows that $b l$ mutant produces $93 \%$ less sclareol and $94 \%$ less linalyl acetate compared to nonglabrous WT plants (Fig. 6h). Since the beardless phenotype is linked to the drastic reduction of metabolite production, we concluded that the decrease of sclareol and linalyl acetate content is due to the absence of large capitate GTs, and that large capitate GTs are major sclareol and linalyl acetate production sites.

\section{Discussion}

The epidermis of clary sage calyces develops GTs at high density (Fig. S1). GTs are known to produce specialized metabolites, including flavonoids, acylsugars, and terpenoids ${ }^{11,23,25,45}$. In this study, we provide converging evidence that sclareol and linalyl acetate, respectively a diterpene and a monoterpene, are produced in clary sage calyx GTs. First, $[\mathrm{L}+\mathrm{K}]^{+},[\mathrm{L}+\mathrm{L}+\mathrm{K}]^{+},[\mathrm{S}+\mathrm{K}]^{+}$, and $[\mathrm{S}+\mathrm{S}+\mathrm{K}]^{+}$ions were detected on calyx epidermis by mass spectrometry imaging and coincide with large capitate GTs (Fig. 4). Secondly, gene expression analyses show that genes coding for enzymes involved in the MEP pathway and for diterpene synthases required for sclareol biosynthesis are expressed at high levels in isolated GTs compared to the rest of the calyx (Fig. 5). Lastly, the beardless (bl) mutant, a clary sage line with no large capitate GTs, produces 94\% less linalyl acetate and 93\% less sclareol (Fig. 6). Taken together, these results demonstrate that GTs are the main site of sclareol and linalyl acetate biosynthesis. In particular, large capitate GTs appear to be responsible for the major part of the sclareol and linalyl acetate production in the clary sage calyces.

Peltate and capitate GTs differ in the way they secrete chemicals. Compounds secreted by capitate GTs are regularly released at the plant surface ${ }^{19,23,46}$. In clary sage, scanning electron microscopy observation of a freshly cut mature calyx suggests that capitate GTs secrete their content. Indeed, spills of electron-dense material were visible on many capitate GT stalks (Fig. S6). The use of a pin to puncture a large capitate glandular head confirmed that this electron-dense material comes from capitate GT heads (Fig. S6). The spilling of capitate GT content could explain the $[\mathrm{S}+\mathrm{K}]^{+}$ion distribution pattern over the calyx epidermis. Therefore, sclareol present on calyx epidermis, detected in the form of $[\mathrm{S}+\mathrm{K}]^{+}$ions, could initially be produced in GT heads and spread over pavement cells along with the rest of glandular head content (Fig. 4). This process of accumulation was shown to occur in the case of the diterpene duvatrienediol in Nicotiana tabacum $^{47}$.

Our scanning electron microscopy observations (Figs. S1 and S6) do not confirm the presence of sclareol crystals described by Caissard et al. ${ }^{15}$ at the surface of calyx epidermis. It is important to note that samples used in the study conducted by Caissard et al. ${ }^{15}$ were collected in the field, while our samples were collected on clary sage plants cultivated in the greenhouse. Less than a day after harvest, clary sage calyces collected in the field were covered with crystals, indicating that dehydration facilitates sclareol crystallization ${ }^{15}$. Consistently, we could see sclareol crystals rapidly forming when calyces were heated by a lamp during microscopy observations (Fig. S7). Moreover, sclareol crystals observed by Caissard et al. ${ }^{15}$ were not evenly distributed on the calyx epidermis and were clustered in patches. Similarly, splashes of gland content that we observed by scanning electron microscopy were scattered over calyx epidermis (Figs. S6 and S7). In the field, sclareol crystals may form progressively from splashes of gland content upon dehydration and evaporation of more volatile compounds like linalyl acetate (Fig. S7). This hypothesis was already suggested by Caissard et al. ${ }^{15}$.

Peltate GTs accumulate metabolites under a thick cuticle that ruptures upon mechanical stimulation, for example in contact with an insect ${ }^{46,48}$. They are known to produce volatile monoterpenes and were previously shown to contain sclareol ${ }^{25,45}$. Indeed, it is surprising that no sclareol and linalyl acetate signals could be associated with peltate GTs (Fig. 4). The thick cuticle covering their storage cavity may prevent their content from being ionized upon laser impact ${ }^{49,50}$.

Crosstalk between MVA and MEP pathways occurs when prenyl intermediates accumulate in one of the two corresponding compartments and the excess amount is transferred to the other compartment to supply the other pathway $^{37}$. Such transfers are observed upon treatment with an MVA or MEP pathway-specific inhibitor, but also under particular physiological conditions in specific tissues or at given developmental stages. Notably, transport of prenyl intermediates from plastids to cytosol frequently occurs in photosynthetic organs ${ }^{26}$, whereas transport from cytosol to plastids has been previously suggested to sustain carotenoid and gibberellin production in etiolated 
seedlings ${ }^{51}$. Interestingly, genes involved in photosynthesis are expressed at low level, if at all, in isolated GTs compared to clary sage calyces before abrasion (Fig. 5), suggesting that the photosynthetic activity of GT cells is low compared to other calyx cells. Therefore, we hypothesized that the MVA pathway could indirectly contribute to sclareol and linalyl acetate biosynthesis in clary sage calyces.

Isotope labeling strategies are powerful tools to study metabolic fluxes and have been successful to characterize the metabolism of many plant species ${ }^{33}$. Notably, the terpenoidspecific patterns obtained with $1-{ }^{13} \mathrm{C}$-glucose labeling are useful to analyze the contribution of the MVA and MEP pathways to the production of metabolites of interest, as was shown with our strategy to assess the biosynthetic origin of sclareol and linalyl acetate (Figs. 2 and 3; Fig. S4). The strong impact of an MEP pathway inhibitor already suggested its involvement in sclareol and linalyl acetate biosynthesis (Fig. 2). However, it could be argued that the drop observed in sclareol and linalyl acetate content is due to a decrease in photosynthetic activity caused by the inhibition of carotenoid synthesis by $\mathrm{FOS}^{33}$. The feeding of clary sage inflorescence stems with $1{ }^{13} \mathrm{C}$-glucose together with FOS rules out this hypothesis and demonstrates that sclareol and linalyl acetate both originate from the MEP pathway (Fig. 3). These results are consistent with the localization of clary sage diterpene synthases involved in sclareol biosynthesis, as these enzymes were shown to be targeted to plastids, the compartment where the MEP pathway is localized ${ }^{12}$.

GTs have been reported to be non-photosynthetic in other Lamiaceae species, including mint ${ }^{45}$. If clary sage GTS are not photosynthetic, as suggested by gene expression analyses (Fig. 5), carbon assimilates must be transported from neighboring cells to GTs to supply MEP pathway activity. A recent study demonstrated that although being photosynthetic, tomato type VI GTs rely on leaf sucrose to maintain their high metabolic activity ${ }^{52}$. This conclusion emerged from the comparison of ${ }^{13} \mathrm{C}$ incorporation in primary metabolites of leaves and isolated type VI GTS during ${ }^{13} \mathrm{CO}_{2}$ labeling. The same approach could be used in clary sage to analyze the contribution of sucrose from nonglandular cells to the GT metabolism.

Since sclareol and linalyl acetate are mainly produced in GTs, increasing GT density could be a promising approach to increase sclareol and EO production in clary sage. This strategy is currently being developed to enhance the production of the antimalarial sesquiterpene artemisinin in Artemisia annua; the overexpression of transcription factors positively regulating GT initiation significantly enhanced GT density and artemisinin yield without any adverse effect on plant growth and fitness ${ }^{53-55}$. Moreover, since sclareol and linalyl acetate are MEP-derived in clary sage calyces (Fig. 5), enhancing MEP pathway activity is another approach to increase sclareol and linalyl acetate content. This strategy has already been implemented successfully to enhance the production of abietane diterpenes in clary sage roots ${ }^{56}$. The ectopic expression of AtDXS and AtDXR genes in hairy roots led to a 2.2- and 3.3-fold increase in abietane diterpene content, respectively, and some lines overexpressing AtDXR even grew faster than the control, thereby combining higher abietane diterpene content and improved growth ${ }^{56}$. Therefore, in addition to improving our understanding of terpenoid production in the Lamiaceae, our results highlight interesting avenues for the targeted genetic enhancement of clary sage performances, which could benefit the flavor and fragrance industry.

\section{Materials and methods Plant material}

S. sclarea seeds from the "Vatican White" population were purchased from Jelitto (Germany). The beardless mutant was generated after seed treatment with ethyl methanesulfonate (EMS). Seeds were immersed in a solution of $0.5 \%$ EMS $(\mathrm{w} / \mathrm{v})$ for $16 \mathrm{~h}$ at room temperature with stirring. Treated seeds were grown in a tunnel and planted as seedlings in the field. Offspring plants were screened for altered phenotypes.

WT and mutant plants were grown in pots for 1 month in a growth chamber $\left(16 \mathrm{~h}\right.$ of the day; $27^{\circ} \mathrm{C}$ during the day, $21^{\circ} \mathrm{C}$ at night; $60 \%$ hygrometry) and then 3-6 months in the greenhouse $\left(24^{\circ} \mathrm{C}\right.$ from 6 a.m. to $10 \mathrm{p}$. m., $20^{\circ} \mathrm{C}$ from 10 p.m. to 6 a.m.; $60 \%$ hygrometry). Pots were moved outdoor at the end of autumn for natural vernalization and left outdoor until flowering. For scanning electron microscopy and LDI-FT-ICR experiments, WT plants were moved back to the greenhouse 2 months before analysis.

\section{Scanning electron microscopy and trichome numbering}

Flower buds ( $2 \mathrm{~mm}$ long) and mature calyces (harboring a wilted flower) were collected from WT "Vatican White" plants cultivated in the greenhouse $\left(24{ }^{\circ} \mathrm{C}\right.$ from 6 a.m. to 10 p.m., $20^{\circ} \mathrm{C}$ from 10 p.m. to $6 \mathrm{a}$. $\mathrm{m}$.; $60 \%$ hygrometry). Freshly cut organs were introduced in the observation chamber of a scanning electron microscope (SEM, Helios NanoLab 660 instrument, FEI) without any treatment. Observation of calyx abaxial face (outer face) was performed with the voltage set to $0.35 \mathrm{kV}$.

For trichome numbering, freshly cut mature calyces were observed with an environmental SEM (MEB SH1500, Hirox) without metallization or any other sample preparation. Portions of $1.70 \mathrm{~mm} \times 2.45 \mathrm{~mm}$ of the abaxial face were scanned at low pressure. The Cell Count Plugin of ImageJ (http://rsb.info.nih.gov/ij) was used to calculate trichome density. 


\section{Metabolite localization by LDI-FT-ICR}

Mature calyx samples, harboring wilted petals, were collected from the "Vatican White" variety of clary sage cultivated in a greenhouse. The zone located at the junction of the upper and the lower lip of the calyx, measuring approximately $2 \mathrm{~mm} \times 4 \mathrm{~mm}$, was fixed onto a conductive microscope slide with conductive doublesided tape. Optical images showing top views of calyx samples were taken using a zoom stereomicroscope (AxioZoom V16, Zeiss). Three calyces were then analyzed by mass spectrometry imaging. Matrix-free laserdesorption-ionization was performed using the MALDI source of the SolariX XR 9.4 Tesla FT-ICR mass spectrometer (Bruker). Sampling was performed using the Smart Beam II laser at $25 \%$ of its power to avoid sample damage. The distance between the 2 sampling points was set to $25 \mu \mathrm{m}$. The spectra were recorded at $120,000 \mathrm{high}$ mass resolution at $\mathrm{m} / \mathrm{z} 150$ for a mass range of $\mathrm{m} / \mathrm{z}$ 50-1000. Data analysis was performed with the SCiLS Lab 2019b Pro software (Bruker). Data were normalized with the total ion current (TIC). To improve data visualization, for each ion of interest, the $0.3 \%$ spots with the highest signal were all displayed with the maximum brightness level using the "hotspot removal" function of the software.

\section{Identification of the MEP pathway genes}

To generate the sequence of DXS2 (DXP-synthase 2), DXR (DXP-reductoisomerase), MCT (MEP-cytidylyltransferase), CMK (CDP-ME kinase), MDS (MEcPP synthase), HDS (HMBPP-synthase), HDR (HMBPPreductase), and GGPPS (geranylgeranyl diphosphate synthase) genes in S. sclarea, nucleotide sequences of the homologous genes were retrieved from Salvia miltiorrhiza, Salvia splendens, and Mentha longifolia genome assemblies $^{22,57,58}$. Nucleotide sequences were aligned and conserved domains were selected to design polymerase chain reaction (PCR) primers. PCR amplification was performed using cDNA library from $S$. sclarea mature calyces. The sequences of the $3^{\prime}$ - and $5^{\prime}$-ends of the MEP genes were obtained by Rapid Amplification of cDNA Ends (RACE) using the Marathon ${ }^{\mathrm{Tm}}$ cDNA amplification kit (Clontech). The full-length sequences are listed in Supplementary sequence data.

\section{GT isolation and gene expression analysis}

GTs were isolated from mature calyces as described by Amme et al. ${ }^{59}$ with some modifications. Briefly, flower buds and calyces were collected from "Vatican White" plants, placed in $50 \mathrm{~mL}$ Falcon tubes, and frozen in liquid nitrogen. Glass beads of 500-600 $\mu \mathrm{m}$ diameters, purchased from Sigma-Aldrich, were poured on flower buds in presence of liquid nitrogen and GTs were mechanically abraded from the epidermis by shaking with a vortex mixer for $30 \mathrm{~s}, 10$ times. The mixture was filtered through a sieve with a pore size of $200 \mu \mathrm{m}$ (Sefar) to separate GTs from glass beads and remaining tissue. The purity of GTs was validated by MZ116F stereomicroscopy (Leica).

Total RNAs were isolated using TRIzol (Invitrogen) and treated with DNase I (Thermo Scientific) to remove contaminating DNA. Complementary DNA was synthesized from $1 \mu \mathrm{g}$ of total RNA using the SuperScript II First-Strand Synthesis System with oligo(dT)20 primers (Invitrogen), according to the manufacturer's instructions. Quantitative PCR was performed with MESA GREEN qPCR MasterMix Plus (Eurogentech) and $200 \mathrm{nM}$ of each primer in a total volume of $10 \mu \mathrm{L}$. Four biological replicates and three technical replicates were analyzed using the CFX384 Real-Time PCR System (Bio-Rad) with the following cycling program: $5 \mathrm{~min} 95^{\circ} \mathrm{C}$ followed by 40 cycles of $15 \mathrm{~s}$ at $95^{\circ} \mathrm{C}$ and $1 \mathrm{~min}$ at $60^{\circ} \mathrm{C}$. Transcript levels were normalized to the transcript level of ACTIN and GAPDH housekeeping genes. Primers used in this study are listed in Supporting Information, Table S1.

\section{Treatment with terpene biosynthesis inhibitors}

MEV and FOS were purchased from Sigma-Aldrich. Stock solutions $(50 \mathrm{mM})$ were prepared in ethanol and water, respectively. Nutritive solution containing $0,1,10$, or $100 \mu \mathrm{M}$ of inhibitor was prepared in $5 \mathrm{~mL}$ vials (Murashige and Skoog basal salt mixture (Sigma-Aldrich); glucose 5\% w/v (Euromedex); PPM $^{\mathrm{TM}} 0.1 \% \mathrm{v} / \mathrm{v}$ (Plant Cell Technology); ethanol $0.2 \% \mathrm{v} / \mathrm{v}$ ). Clary sage inflorescence axillary stems were cut between the third and the fourth node (about $10 \mathrm{~cm}$ from the apex). Each stem was immediately placed in a vial in a way that its extremity was touching the bottom of the vial and dipped in nutritive solution. Treatment was performed by leaving inflorescence stems on the bench for 5 days. Calyces were sampled from each inflorescence stem, immediately frozen in liquid nitrogen, and stored at $-80^{\circ} \mathrm{C}$ before sclareol and linalyl acetate quantification by GC-MS. Sampled calyces were at the flower bud stage at the beginning of the treatment and were mature at the end of the treatment.

\section{Isotope labeling and analysis by ${ }^{13} \mathrm{C}-\mathrm{NMR}$}

Clary sage inflorescence axillary stems were cut and fed with a nutritive solution containing $1{ }^{13} \mathrm{C}$-glucose $5 \% \mathrm{w} / \mathrm{v}$ (Sigma-Aldrich), following the protocol described above for terpene biosynthesis inhibitor treatment. After 5 days, flower buds and young calyces were sampled from each inflorescence stem, immediately frozen in liquid nitrogen, and stored at $-80{ }^{\circ} \mathrm{C}$ before further analysis. Calyces collected on one inflorescence stem were immersed in $8 \mathrm{~mL}$ of hexane without grinding to extract metabolites present at the surface. After $2 \mathrm{~h}$ of agitation, the extract was centrifuged at $13,000 \mathrm{rpm}$ for $10 \mathrm{~min}$ to eliminate potential dust. Hexane was evaporated by leaving the samples under the fume hood for 2-3 days. The dry 
extract was resuspended in $600 \mu \mathrm{L}$ of $\mathrm{CDCl}_{3}$ for ${ }^{13} \mathrm{C}$-NMR analysis. ${ }^{13} \mathrm{C}$-NMR analyses were performed using an Ascend $400 \mathrm{MHz}$ NanoBay instrument equipped with an AVANCE III HD console and a Prodigy BBO cryoprobe $\left({ }^{31} \mathrm{P}-{ }^{15} \mathrm{~N}\right)$ (Bruker). Analyses were performed at $277 \mathrm{~K}$ without tube spinning, using a proton-decoupled (decoupling sequence waltz16) carbon pulse program (zgig) with $90^{\circ}$ pulses of $9.75 \mu \mathrm{s}$ at $41 \mathrm{~W}$ for ${ }^{13} \mathrm{C}$. The relaxation delay (D1) was set to $15 \mathrm{~s}$ to enable complete acquisition of the signal corresponding to ${ }^{13} \mathrm{C}$ nuclei relaxation. To obtain a good signal-to-noise ratio, 5096 scans were launched and data were analyzed using the TopSpin software (Bruker). The attribution of each peak of the spectrum to carbon of sclareol or linalyl acetate (Supporting Information, Table S2) was performed using ${ }^{1} \mathrm{H}, \mathrm{COSY}, \mathrm{HSQC}$, and HMBC experiments and inspired by previously published data ${ }^{29,60}$. The potential incorporation of ${ }^{13} \mathrm{C}$ at a given position was evaluated using the following labeling ratio: (Peak areafeeding - Peak areacontrol $/$ /Peak area control $_{\text {. }}$

\section{Sclareol and linalyl acetate quantification by GC-MS}

Clary sage calyces were immersed in hexane $(1.5 \mathrm{~mL}$ per calyx) without grinding to extract metabolites mainly present at the surface. 10-undecen-1-ol was employed as internal standard and was added in the solvent before extraction at a concentration of $0.75 \mathrm{mM}$. After $2 \mathrm{~h}$ of agitation, the extract was centrifuged at $13,000 \mathrm{rpm}$ for $10 \mathrm{~min}$ to eliminate potential dust. Extracts were directly analyzed using a 7890B/5977A GC-MS system from Agilent, according to a protocol adapted from Laville et al. ${ }^{16}$. The system was equipped with a $10 \mathrm{~m}$ guard column and an Rxi-5Sil MS column (length, $30 \mathrm{~m}$; inner diameter, $0.25 \mathrm{~mm}$; film thickness, $0.25 \mu \mathrm{m}$ ) (Restek, Bellefonte, PA, USA). One microlitre of the sample was injected with a split ratio of 30:1. The oven temperature was set to $110^{\circ} \mathrm{C}$ for $2 \mathrm{~min}$, then increased to $270^{\circ} \mathrm{C}$ at a rate of $10^{\circ} \mathrm{C} / \mathrm{min}$, and finally set to $270^{\circ} \mathrm{C}$ for $2 \mathrm{~min}$. Other temperatures were set as follows: injector, $270^{\circ} \mathrm{C}$; transfer line, $270^{\circ} \mathrm{C}$; source, $230^{\circ} \mathrm{C}$; quadrupole, $150^{\circ} \mathrm{C}$. The carrier gas was helium at a constant flow of $1 \mathrm{~mL} /$ min. The quadrupole mass spectrometer was switched on after a solvent delay of $5 \mathrm{~min}$ and was programmed to scan from 35 to $350 \mathrm{u}$. Data analysis was carried out with the MassHunter Quantitative Analysis software from Agilent. Sclareol and linalyl acetate were identified by comparison with analytical standards purchased from Sigma-Aldrich. Absolute quantification of sclareol and linalyl acetate was performed using a calibration curve prepared with analytical standards.

\section{Acknowledgements}

This work was supported by the Plant Biology and Breeding department in INRA, the grants Program LabEx Saclay Plant Sciences-SPS (ANR-10-LABX-40-
SPS). Financial support from the National FT-ICR network (FR 3624 CNRS) is gratefully acknowledged.

We thank P. Audigier, Holger Ornstrup, and F. Vion for plant handling, the cell biology imaging platform, and research facilities provided by the Institute of Plant-Science Paris-Saclay (IPS2).

\section{Author details}

${ }^{1}$ Université Paris-Saclay, CNRS, INRAE, Univ Evry, Institute of Plant Sciences Paris-Saclay (IPS2), 91405 Orsay, France. ${ }^{2}$ Molecular Chemistry Laboratory (LCM), UMR 9168, CNRS, Ecole Polytechnique, Institut Polytechnique de Paris, Route de Saclay, 91128 Palaiseau Cedex, France. ${ }^{3}$ Laboratory of Mechanics of Soils, Structures and Materials (MSSMAT), UMR 8579, CNRS, Ecole

CentraleSupélec, Université Paris-Saclay, Bâtiment Eiffel, 8-10 rue Joliot-Curie, 91190 Gif-Sur-Yvette, France

\section{Author contributions}

S.D., F.G., M.D., A. Be., and A.Bo. designed the project. C.C., S.D., C.C., H.M., C.M., E.N., L.K., and E.H. performed the experiments. C.C., S.D., F.G., C.M., E.N., and A. Bo. interpreted the data. C.C. drafted the paper. S.D., M.D., A. Be, and A. Bo. corrected the paper.

\section{Data availability}

The raw datasets for GC-MS, NMR, and LDI-FTICR experiments are available from the corresponding author on reasonable request. All sequences of Salvia sclarea MEP pathway genes generated in this study are available in the

Supplementary information (Supplementary sequence data).

Conflict of interest

The authors declare no competing interest.

Supplementary information The online version contains supplementary material available at https://doi.org/10.1038/s41438-021-00640-w.

Received: 10 April 2021 Revised: 9 July 2021 Accepted: 22 July 2021

Published online: 01 October 2021

\section{References}

1. Clarke, R. The origin of ambergris. LAJAM 5, 7-21 (2006).

2. Ohloff, G. The Fragrance of Ambergris. 535-573 (ed E.T. Theimer) (Academic Press, 1982).

3. Rowland, S. J., Sutton, P. A. \& Knowles, T. D. J. The age of ambergris. Nat. Prod. Res. 33, 3134-3142 (2019).

4. Ohloff, G., Schulte-Elte, K. H. \& Müller, B. L. Formation of ambergris odorants from ambrein under simulated natural conditions. Helv. Chim. Acta 60, 2763-2766 (1977).

5. Barrero, A. F., Altarejos, J., AlvarezManzaneda, E. J., Ramos, J. M. \& Salido, S. Synthesis of (+/-)-ambrox from (E)-nerolidol and beta-ionone via allylic alcohol [2,3] sigmatropic rearrangement. J. Org. Chem. 61, 2215-2218 (1996).

6. Barrero, A. F., Alvarezmanzaneda, E. J., Altarejos, J., Salido, S. \& Ramos, J. M. Synthesis of ambrox(R) from (-)-sclareol and (+)-cis-abienol. Tetrahedron 49, 10405-10412 (1993)

7. Zerbe, P. \& Bohlmann, J. Plant diterpene synthases: exploring modularity and metabolic diversity for bioengineering. Trends Biotechnol. 33, 419-428 (2015).

8. Foutami, I. J., Mariager, T., Rinnan, R., Barnes, C. J. \& Ronsted, N. Hundred fifty years of herbarium collections provide a reliable resource of volatile terpenoid profiles showing strong species effect in four medicinal species of salvia across the mediterranean. Front. Plant Sci. 9, 1877 (2018).

9. Wagner, S., Pfleger, A., Mandl, M. \& Böchzelt, H. Changes in the qualitative and quantitative composition of essential oils of clary sage and roman chamomile during steam distillation in pilot plant scale. Distillation-Advances from Modelling to Application, 141-158 (2012).

10. Nasermoadeli, S. \& Rowshan, V. Comparison of Salvia sclarea L. essential oil components in wild and field population. Int. J. Agric. Crop Sci. 4, 1997-2000 (2013).

11. Lattoo, S. K., Dhar, R. S., Dhar, A. K., Sharma, P. R. \& Agarwal, S. G. Dynamics of essential oil biosynthesis in relation to inflorescence and glandular ontogeny in Salvia sclarea. Flavour Fragr. J. 21, 817-821 (2006). 
12. Caniard, A. et al. Discovery and functional characterization of two diterpene synthases for sclareol biosynthesis in Salvia sclarea (L.) and their relevance for perfume manufacture. BMC Plant Biol. 12, 119 (2012).

13. Kuzma, L. et al. Chemical composition and biological activities of essential oil from Salvia sclarea plants regenerated in vitro. Molecules 14, 1438-1447 (2009).

14. Sharopov, F. S. \& Setzer, W. N. The essential oil of Salvia sclarea L. from Tajikistan. Rec. Nat. Prod. 6, 75-79 (2012).

15. Caissard, J. C. et al. Extracellular localization of the diterpene sclareol in clary sage (Salvia sclarea L., Lamiaceae). PloS ONE 7, e48253 (2012).

16. Laville, R. et al. Amphilectane diterpenes from Salvia sclarea: biosynthetic considerations. J. Nat. Prod. 75, 121-126 (2012).

17. Yang, S. X. et al. One-pot synthesis of (-)-ambrox. Sci. Rep. 6, 32650 (2016).

18. Lange, B. M. The evolution of plant secretory structures and emergence of terpenoid chemical diversity. Annu. Rev. Plant Biol. 66, 139-159 (2015).

19. Tissier, A. Plant secretory structures: more than just reaction bags. Curr. Opin. Biotechnol. 49, 73-79 (2018).

20. Sallaud, $C$. et al. Characterization of two genes for the biosynthesis of the labdane diterpene Z-abienol in tobacco (Nicotiana tabacum) glandular trichomes. Plant J. 72, 1-17 (2012).

21. Spyropoulou, E. A., Haring, M. A. \& Schuurink, R. C. Expression of terpenoids 1, a glandular trichome-specific transcription factor from tomato that activates the terpene synthase 5 promoter. Plant Mol. Biol. 84, 345-357 (2014).

22. Vining, K. J. et al. Draft genome sequence of Mentha longifolia and development of resources for mint cultivar improvement. Mol. Plant 10, 323-339 (2017).

23. Werker, E. Function of essential oil-secreting glandular hairs in aromatic plants of the lamiaceae-a review. Flavour Fragr. J. 8, 249-255 (1993).

24. Werker, E., Ravid, U. \& Putievsky, E. Glandular hairs and their secretions in the vegetative and reproductive-organs of salvia-sclarea and salvia-dominica. Isr. J. Bot. 34, 239-252 (1985).

25. Schmiderer, C., Grassi, P., Novak, J., Weber, M. \& Franz, C. Diversity of essentia oil glands of clary sage (Salvia sclarea L., Lamiaceae). Plant Biol. 10, 433-440 (2008).

26. Tholl, D. Biosynthesis and biological functions of terpenoids in plants. Adv. Biochem. Eng. Biot. 148, 63-106 (2015).

27. Schalk, M. et al. Toward a biosynthetic route to sclareol and amber odorants. J. Am. Chem. Soc. 134, 18900-18903 (2012).

28. Gunnewich, N. et al. A diterpene synthase from the clary sage Salvia sclarea catalyzes the cyclization of geranylgeranyl diphosphate to (8R)-hydroxycopalyl diphosphate. Phytochemistry 91, 93-99 (2013)

29. Fowler, D. J., Hamilton, J. T. G., Humphrey, A. J. \& O'Hagan, D. Plant terpene biosynthesis. The biosynthesis of linalyl acetate in Mentha citrata. Tetrahedron Lett. 40, 3803-3806 (1999).

30. Zaks, A., Davidovich-Rikanati, R., Bar, E., Inbar, M. \& Lewinsohn, E. Biosynthesis of linalyl acetate and other terpenes in lemon mint (Mentha aquatica var. citrata, Lamiaceae) glandular trichomes. Isr. J. Plant Sci. 56, 233-244 (2008).

31. Jomaa, $H$. et al. Inhibitors of the nonmevalonate pathway of isoprenoid biosynthesis as antimalarial drugs. Science 285, 1573-1576 (1999).

32. Lichtenthaler, H. K. Non-mevalonate isoprenoid biosynthesis: enzymes, genes and inhibitors. Biochem. Soc. Trans. 28, 785-789 (2000).

33. Lipko, A. \& Swiezewska, E. Isoprenoid generating systems in plants-a handy toolbox how to assess contribution of the mevalonate and methylerythritol phosphate pathways to the biosynthetic process. Prog. Lipid Res. 63, 70-92 (2016).

34. Reed, J. \& Osbourn, A. Engineering terpenoid production through transient expression in Nicotiana benthamiana. Plant Cell Rep. 37, 1431-1441 (2018).

35. Opitz, S., Nes, W. D. \& Gershenzon, J. Both methylerythritol phosphate and mevalonate pathways contribute to biosynthesis of each of the major isoprenoid classes in young cotton seedlings. Phytochemistry 98, 110-119 (2014).

36. Wolwer-Rieck, U., May, B., Lankes, C. \& Wust, M. Methylerythritol and mevalonate pathway contributions to biosynthesis of mono-, sesqui-, and diterpenes in glandular trichomes and leaves of Stevia rebaudiana Bertoni. J. Agr. Food Chem. 62, 2428-2435 (2014).

37. Liao, P., Hemmerlin, A., Bach, T. J. \& Chye, M. L. The potential of the mevalonate pathway for enhanced isoprenoid production. Biotechnol. Adv. 34, 697-713 (2016).
38. Alberts, A. W. et al. Mevinolin-a highly potent competitive inhibitor of hydroxymethylglutaryl-coenzyme-a reductase and a cholesterol-lowering agent. Proc. Natl Acad. Sci. USA 77, 3957-3961 (1980).

39. Hall, R. et al. Plant metabolomics: the missing link in functional genomics strategies. Plant Cell 14, 1437-1440 (2002).

40. Amster, I. J. Fourier transform mass spectrometry. J. Mass Spectrom. 31, 1325-1337 (1996).

41. Ding, J. \& Anderegg, R. J. Specific and nonspecific dimer formation in the electrospray ionization mass spectrometry of oligonucleotides. J. Am. Soc. Mass Spectrom. 6, 159-164 (1995).

42. Stefansson, M., Sjöberg, P. J. R. \& Markides, K. E. Regulation of multimer formation in electrospray mass spectrometry. Anal. Chem. 68, 1792-1797 (1996).

43. Kamel, A. M., Brown, P. R. \& Munson, B. Effects of mobile-phase additives, solution $\mathrm{pH}$, ionization constant, and analyte concentration on the sensitivities and electrospray ionization mass spectra of nucleoside antiviral agents. Anal. Chem. 71, 5481-5492 (1999).

44. Lange, B. M. et al. Probing essential oil biosynthesis and secretion by functional evaluation of expressed sequence tags from mint glandular trichomes. Proc. Natl Acad. Sci. USA 97, 2934-2939 (2000).

45. Lange, B. M. \& Turner, G. W. Terpenoid biosynthesis in trichomes-current status and future opportunities. Plant Biotechnol. J. 11, 2-22 (2013).

46. Figueiredo, A. C., Barroso, J. G., Pedro, L. G. \& Scheffer, J. J. C. Factors affecting secondary metabolite production in plants: volatile components and essential oils. Flavour Fragr. J. 23, 213-226 (2008).

47. Keene, C. K. \& Wagner, G. J. Direct demonstration of duvatrienediol biosynthesis in glandular heads of tobacco trichomes. Plant Physiol. 79 1026-1032 (1985).

48. Tissier, A. Glandular trichomes: what comes after expressed sequence tags? Plant J. 70, 51-68 (2012).

49. Dong, Y. et al. Sample preparation for mass spectrometry imaging of plant tissues: a review. Front. Plant Sci. 7, 60 (2016).

50. Thunig, J., Hansen, S. H. \& Janfelt, C. Analysis of secondary plant metabolites by indirect desorption electrospray ionization imaging mass spectrometry. Anal. Chem. 83, 3256-3259 (2011).

51. Rodriguez-Concepcion, M. et al. Distinct light-mediated pathways regulate the biosynthesis and exchange of isoprenoid precursors during Arabidopsis seedling development. Plant Cell 16, 144-156 (2004).

52. Balcke, G. U. et al. Multi-omics of tomato glandular trichomes reveals distinct features of central carbon metabolism supporting high productivity of specialized metabolites. Plant Cell 29, 960-983 (2017).

53. Yan, T. X. et al. HOMEODOMAIN PROTEIN 1 is required for jasmonatemediated glandular trichome initiation in Artemisia annua. N. Phytol. 213, 1145-1155 (2017).

54. Yan, T. X. et al. A novel HD-ZIP IV/MIXTA complex promotes glandular trichome initiation and cuticle development in Artemisia annua. N. Phytol. 218, 567-578 (2018).

55. Shi, P. et al. The roles of AaMIXTA1 in regulating the initiation of glandular trichomes and cuticle biosynthesis in Artemisia annua. N. Phytol. 217, 261-276 (2018).

56. Vaccaro, M., Malafronte, N., Alfieri, M., De Tommasi, N. \& Leone, A. Enhanced biosynthesis of bioactive abietane diterpenes by overexpressing AtDXS or AtDXR genes in Salvia sclarea hairy roots. Plant Cell Tiss. Org. 119, 65-77 (2014)

57. $\mathrm{Xu}, \mathrm{H}$. et al. Analysis of the genome sequence of the medicinal plant Salvia miltiorrhiza. Mol. Plant 9, 949-952 (2016).

58. Dong, A. X. et al. High-quality assembly of the reference genome for scarlet sage, Salvia splendens, an economically important ornamental plant. Gigascience 17, giy068 (2018).

59. Amme, S. et al. A proteome approach defines protective functions of tobacco leaf trichomes. Proteomics 5, 2508-2518 (2005).

60. Chain, F. E., Leyton, P., Paipa, C., Fortuna, M. \& Brandan, S. A. FT-IR, FTRaman, UV-visible, and NMR spectroscopy and vibrational properties of the labdane-type diterpene 13-epi-sclareol. Spectrochim. Acta A 138, 303-313 (2015) 